\title{
Compact Weather Sensor Node for Predicting Road Surface Temperature
}

\author{
Taeyoon Eom, ${ }^{1,2}$ Yongsu Kwon, ${ }^{1}$ and Hyoungho $\mathrm{Ko}^{1^{*}}$ \\ ${ }^{1}$ Department of Electronics Engineering, Chungnam National University, \\ 99, Daehak-ro, Yuseong-gu, Daejeon 34134, Republic of Korea \\ ${ }^{2}$ Department of Information System Operation, Korea Institute of Science and Technology Information, \\ 245, Daehak-ro, Yuseong-gu, Daejeon 34141, Republic of Korea
}

(Received April 17, 2020; accepted April 22, 2021)

Keywords: road surface temperature, winter road forecast, weather sensor node

We propose a compact road weather sensor node to predict the road surface temperature. This node is based on the model of the environment and temperature of roads (METRo) developed by the Government of Canada. The model requires an atmospheric forecast, the station configuration, and observation information as inputs. Observation data have commonly been produced by a road weather information system (RWIS), but this system is larger than necessary, and it has been difficult to maintain the surface sensors embedded on roads. We experimentally determined that the air and surface temperatures are key parameters for the model to predict the surface temperature. The proposed node was designed to be compact with an integrated environmental sensor for measuring atmospheric parameters and an infrared (IR) non-contact thermometer to obtain the surface temperature. In field tests with the prototype, we verified the good observation performance of the IR remote sensor by using a standard instrument for measuring the surface temperature. The results of the model based on data obtained by the prototype also showed excellent predictive performance during nighttime. This weather sensor node uses long range (LoRa) technology, which makes it suitable for long-range, low-power, and low-data-rate performance, suggesting the possibility of its commercialization.

\section{Introduction}

Road accidents are caused by the interaction of the road environment, vehicles, and road users. $^{(1)}$ Advanced vehicle safety systems, such as autonomous driving and advanced driver assistance systems, are aimed at controlling the impact of these accident factors. The environmental factors are mainly monitored by a road weather information system (RWIS), but road systems are too extensive for comprehensive monitoring, and it is difficult to predict where accidents will occur. In addition, weather has broad and significant effects on the road environment. Snow, rain, ice, fog, and other weather conditions can impair the ability of drivers to operate their vehicles safely, significantly reducing road capacity and dramatically increasing travel times. Multiple road activities, from road maintenance and construction to shipping,

*Corresponding author: e-mail: hhko@cnu.ac.kr

https://doi.org/10.18494/SAM.2021.3361 
transit, and police operations, are directly affected by inclement weather. ${ }^{(2)}$ For this reason, it is important to establish dense observation networks on roads.

A guideline of the U.S. Federal Highway Administration recommends the use of tower-based sensors within 30 to 50 feet of a road for an RWIS. A typical system consists of various sensors, including air temperature/dew point sensors, wind speed and direction sensors, precipitation sensors, and road surface and subsurface sensors. ${ }^{(3)}$ The road surface sensor is installed in the pavement to measure its temperature and status. However, these sensors are often in contact with car wheels, leading to increased maintenance and reduced reliability. As an alternative to avoid this problem, a method using infrared (IR) has recently been proposed. Figure 1 shows these methods installed on roads. The specifications of sensors used for monitoring road temperature are described in Table 1. By utilizing the latest IR technology, it is possible to retrieve additional information concerning both road temperatures and road conditions. ${ }^{(4)} \mathrm{A}$ remote method can increase the stability of sensor devices and ensure the reliability of data. In addition, it is possible to develop small and practical wireless sensor devices because low-cost IR sensors have already been commercialized. In this study, we constructed a sensor node for detecting the road surface temperature using an inexpensive IR thermometer module.

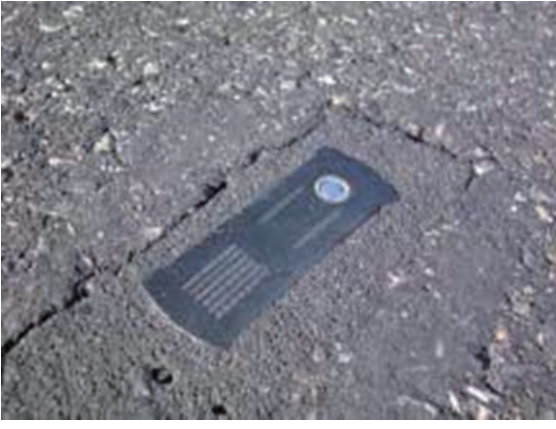

(a)

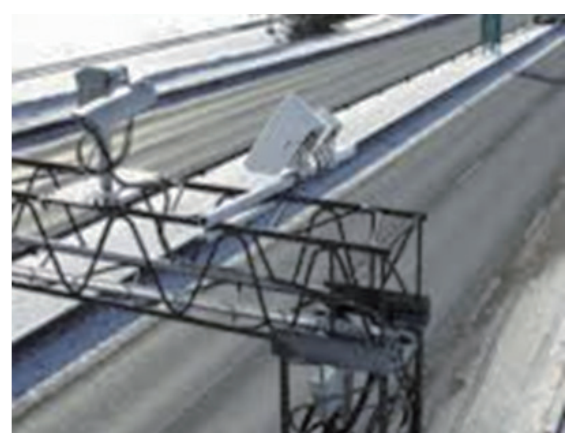

(b)

Fig. 1. (Color online) (a) Road burial method and (b) remote method on tower system.

Table 1

(Color online) Sensors used for monitoring road temperature.

\begin{tabular}{|c|c|c|c|c|}
\hline Name & Photo & Model & Installation & Reference values \\
\hline $\begin{array}{l}\text { Road and runway } \\
\text { surface and depth } \\
\text { sensor (Vaisala) }\end{array}$ & & DRS511 & $\begin{array}{l}\text { Embedded on } \\
\text { road }\end{array}$ & $\begin{array}{l}\text { Temp. range: }-40-60{ }^{\circ} \mathrm{C} \\
\text { Acc.: } \pm 0.1+0.00167 \times T^{\circ} \mathrm{C} \\
\text { Water layer thick.: } 0-7 \mathrm{~mm} \\
\text { Acc.: } \pm 0.1 \mathrm{~mm} \text { under } 1.0 \mathrm{~mm} \\
\text { Surface states: dry, moist, wet, } \\
\text { snowy, icy, frosty, moist and } \\
\text { chemical, wet and chemical }\end{array}$ \\
\hline $\begin{array}{l}\text { Remote surface } \\
\text { temperature sensor } \\
\text { (Vaisala) }\end{array}$ & & DST111 & $\begin{array}{l}\text { Mounted on } \\
\text { tower systems }\end{array}$ & $\begin{array}{l}\text { Remote distance: } 2-15 \mathrm{~m} \\
\text { Temp. range: }-40-60{ }^{\circ} \mathrm{C} \\
\text { Resolution: } 0.1{ }^{\circ} \mathrm{C} \\
\text { Time constant: } 1 \mathrm{~min} \\
\text { Data refresh time: } 30 \mathrm{~s}\end{array}$ \\
\hline
\end{tabular}




\section{Materials and Methods}

\subsection{Model of the environment and temperature of roads (METRo)}

The METRo model, which is a numerical model for forecasting road conditions, was developed for use at Canadian weather centers. This model solves the energy balance between the road surface and the heat conduction in the road material to calculate the temperature evolution; it also accounts for water accumulation on the road in liquid and solid forms. ${ }^{(4)}$ The surface energy balance model, which describes the partitioning of energy fluxes toward and away from the surface, plus a key role in predicting road environments using the weather forecast. Additionally, the road heat-conduction model and water/ice accumulation model help to estimate the lifetime of the water sources on the road surface. The model requires an atmospheric forecast, the station configuration, and observation information as inputs. The forecast data include the atmospheric parameters, which are the air temperature, dew point, rain/snow precipitation quantity since the beginning of the forecast, wind speed, surface pressure, and cloud coverage. In the observation, the input data consist of the air temperature, dew point, road surface temperature, presence of precipitation, wind speed, road condition, and road subsurface temperature. The observation data are commonly produced by an RWIS. ${ }^{(5)}$ Figure 2 shows the process of the METRo model.

The Korea Meteorological Administration (KMA) has highly accurate weather forecasting technology and operates over 600 automated weather stations (AWS), but there is no roadside observation system. Although the Korea Expressway Corporation operates some RWIS stations, these are not enough to observe whole road areas. To overcome this problem, we decided to replace the following variables with data observed at the nearest AWS instead of RWIS:

a. Presence of precipitation

b. Wind speed

We considered that these meteorological variables are available over a sufficiently wide $\operatorname{area}^{(6)}$ to represent the whole road area.

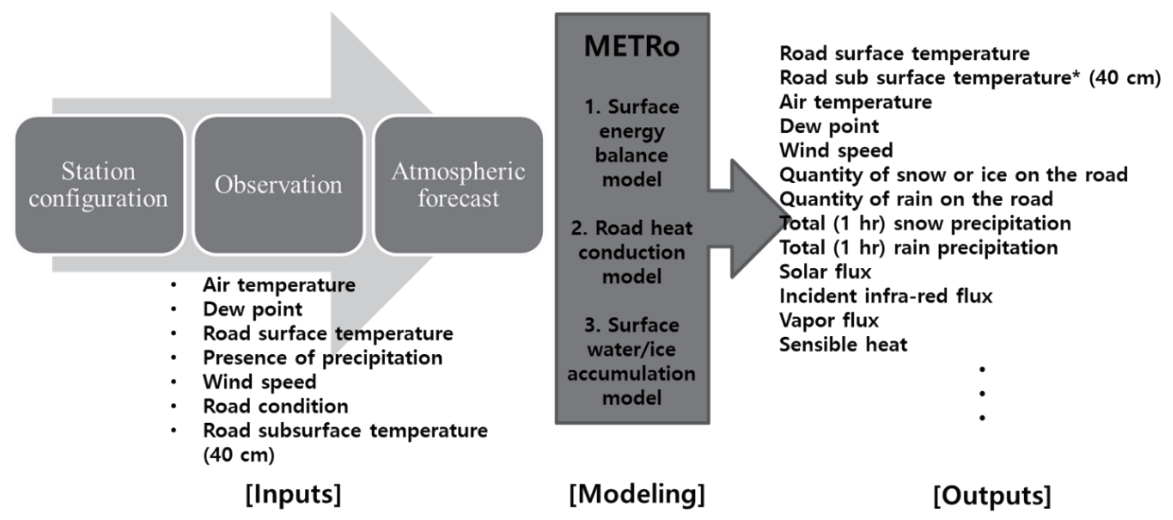

Fig. 2. Process of the METRo model. 


\subsection{Design of the proposed weather sensor node}

The purpose of this design is making a compact weather sensor node as a IoT device. It should be used with the road forecast model. We experimentally determined that the air temperature and surface temperature are key parameters for the model to predict the surface temperature. ${ }^{(6)}$ The specifications of the sensors are described in Table 2: a BME280 module for acquiring the atmospheric parameters and an MLX90614 module for acquiring the road information. To increase the usability of the node, its exterior is designed to have the shape of delineators, which are used frequently to alert pedestrians and drivers with a light reflection. The node was designed using Autodesk Fusion 360, and the frame of the prototype was produced using a 3D printer. Figure 3 shows a photograph of the proposed weather sensor node. It has space for a long range (LoRa) antenna and two 18650 battery cells. LoRa is a wireless technology that provides long-range, low-power, and secure data transmission for machine-to-machine (M2M) and IoT applications.

Table 2

(Color online) Specifications of the sensor modules used in the proposed node.

\begin{tabular}{|c|c|c|c|}
\hline Name & Photo & Reference value & Purpose of use \\
\hline $\begin{array}{l}\text { BME } 280 \\
\text { (Bosch) }\end{array}$ & & $\begin{array}{c}\text { Operating voltage: } 1.71-3.6 \mathrm{~V} \\
\text { Current max: } 3.6 \mu \mathrm{A}, 1 \mathrm{~Hz} \\
\text { Sleep mode consumption: } 0.1 \mu \mathrm{A} \\
\text { Interface: } \mathrm{I}^{2} \mathrm{C} \text { and } \mathrm{SPI} \\
\text { Temp. range: }-40-85, \pm 1.0^{\circ} \mathrm{C} \\
\text { Air press. range: } 300-1100, \pm 1.0 \mathrm{hPa} \\
\text { Relative humi. range: } 0-100, \pm 3 \%\end{array}$ & $\begin{array}{c}\text { Atmospheric parameters, } \\
\text { air temperature, humidity, } \\
\text { and air pressure }\end{array}$ \\
\hline $\begin{array}{l}\text { MLX } \\
90614 \\
\text { (Melexis) }\end{array}$ & & $\begin{array}{l}\text { Operating voltage: } 3.6-5.0 \mathrm{~V} \\
\text { Supply current: } 1.5 \mathrm{~mA} \\
\text { Interface: SMBus } \\
\text { Ambient temp.: }-40-125, \pm 0.5^{\circ} \mathrm{C} \\
\text { Object temp.: }-70-380, \pm 0.5^{\circ} \mathrm{C} \\
\text { Resolution of temp.: } 0.02^{\circ} \mathrm{C}\end{array}$ & $\begin{array}{l}\text { Road temperature and } \\
\text { estimation of road surface } \\
\text { condition }\end{array}$ \\
\hline
\end{tabular}

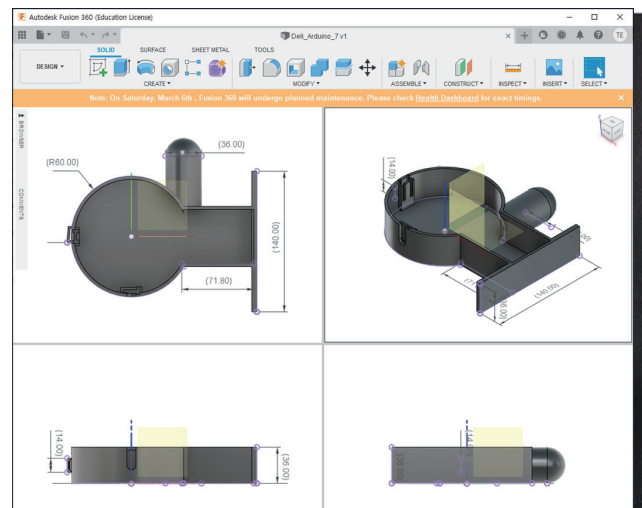

(a)

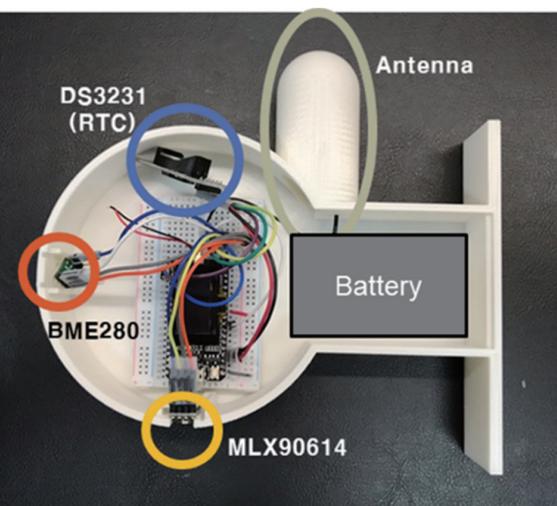

(b)

Fig. 3. (Color online) (a) Fusion 360 tool used to design the exterior and (b) photograph of the prototype. 


\subsection{Road environment forecast system}

Figure 4 shows a diagram of the road environment forecast system. This system consists of a wireless end node, a gateway, and a PC server. The end node and gateway are implemented with a LoRa 32 IoT development board. This board uses an integrated chip including the microcontroller and the wireless module. It offers third-party features such as message queuing telemetry transport (MQTT). Furthermore, the LCD attached on the board is able to monitor the device state and sensing data in real time. The role of the end node is to measure the road environment, air temperature, relative humidity, air pressure, and asphalt surface temperature, and transmit data every $10 \mathrm{~min}$ to the gateway. The interface between the sensors and the MCU uses inter-integrated circuit (I2C) communication with wires. Atmospheric information is measured by a BME280 environmental sensor, and road information is obtained by an MLX90614 IR non-contact thermometer. For power efficiency, a real-time clock module is attached to generate an interrupt signal every $10 \mathrm{~min}$. At the gateway level, the node is directly connected to the PC to send a received message from the end node via a serial UART interface. To deal with emergencies, an SD card is attached to the gateway to prevent accidental data loss and the backed-up data is transferred again when the connection with the server is restored. The gateway node also uses the same board as the end node. The server collects weather forecast information according to a public schedule and runs the road environment forecast model twice a day ( 8 a.m. and 5 p.m.), with data received from the end node. Figure 5 shows the flow of the

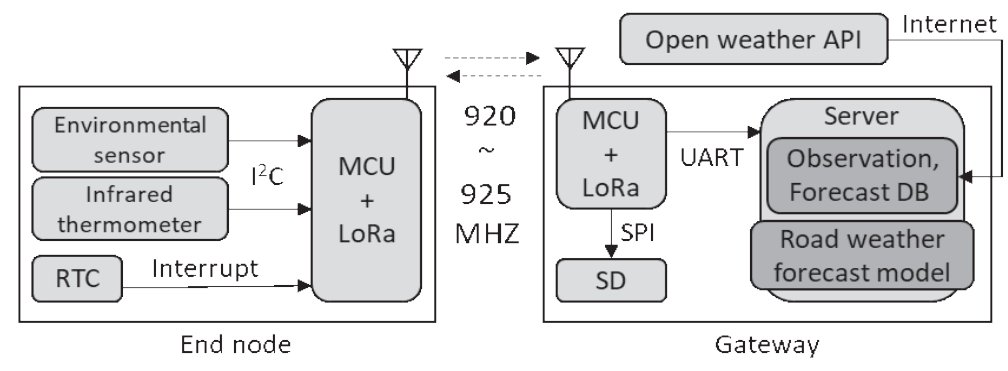

Fig. 4. Diagram of the road environment forecast system.

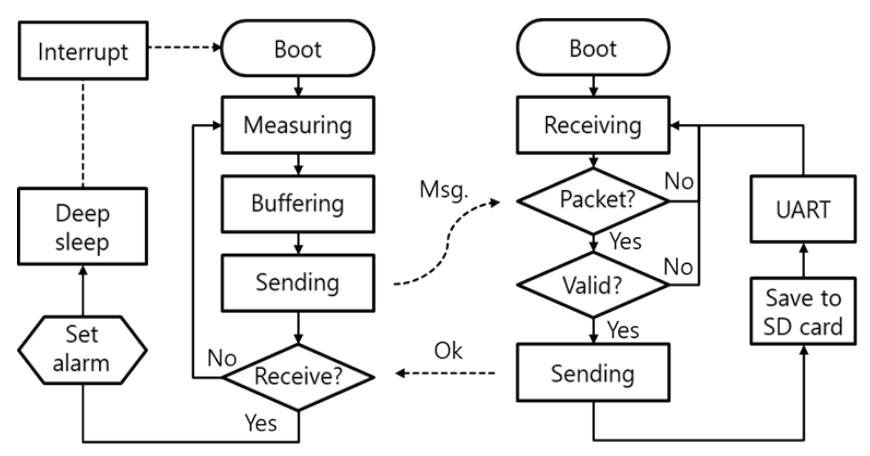

(a)

(b)

Fig. 5. Flowchart of the node communication between (a) end node and (b) gateway node. 
sensor data from the end node to the gateway node. When the end node boots up, the MCU reads data from the sensor modules and constructs a data message with the try number and the node identity. Table 3 shows an example of the buffered message on a packet. The message sent via the LoRa antenna is detected by the gateway node and examined with the node ID. When the message is validated, the gateway node sends an 'OK' sign to the end node and it is switched to the deep sleep mode with an alarm set. The message data is primarily saved in the SD card, and it is transmitted to the PC server and updates the database if UART communication is possible. Table 4 shows the contents of a database file on the PC server. This database is used as input data for observation in the forecast model. Figure 6 shows the photographs of the system in the field test environment. It is divided into the (a) end node and (b) gateway, and the gateway consists of a computer and the (c) gateway node.

Table 3

Message composition of the end node.

\begin{tabular}{lccccccc}
\hline \multirow{2}{*}{$\begin{array}{l}\text { Try } \\
\text { num. }\end{array}$} & \multirow{2}{*}{ Node ID } & \multicolumn{3}{c}{ BME280 } & & \multicolumn{2}{c}{ MLX90614 } \\
\cline { 3 - 4 } \cline { 6 - 7 } & & Air temp. & Air press. & Humi. & & Amb temp. & Obj temp. \\
\hline 0 & METRoNode0 & 22.85 & 1011.73 & 28.06 & & 19.23 & 26.65 \\
0 & METRoNode0 & 22.22 & 1011.59 & 28.05 & & 18.97 & 25.99 \\
0 & METRoNode0 & 18.11 & 1011.46 & 33.37 & & 17.25 & 22.57 \\
0 & METRoNode0 & 21.54 & 1011.29 & 29.06 & & 18.77 & 27.61 \\
0 & METRoNode0 & 19.4 & 1011.09 & 32.41 & & 19.37 & 25.53 \\
\hline
\end{tabular}

Table 4

Contents of data file on PC server.

\begin{tabular}{cc}
\hline$n$ & Contents on data file \\
\hline 1 & RSSI:-109(43Bytes)2020-04-04 11:00 0METRoNode0T22.85P1011.73H28.06A19.23O26.65 \\
2 & RSSI:-107(43Bytes)2020-04-04 11:10 0METRoNode0T22.22P1011.59H28.05A18.97O25.99 \\
3 & RSSI:-106(43Bytes)2020-04-04 11:20 0METRoNode0T18.11P1011.46H33.37A17.25O22.57 \\
4 & RSSI:-107(43Bytes)2020-04-04 11:30 0METRoNode0T21.54P1011.29H29.06A18.77O27.61 \\
5 & RSSI:-107(43Bytes)2020-04-04 11:40 0METRoNode0T19.40P1011.09H32.41A19.37O25.5 \\
& $\vdots$
\end{tabular}

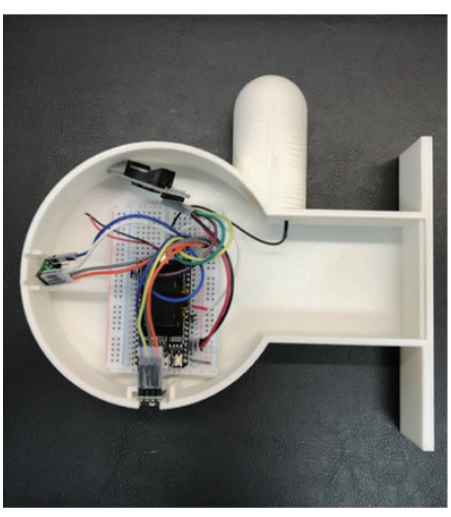

(a)

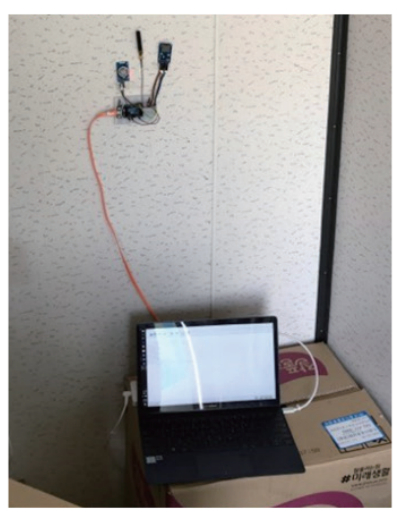

(b)

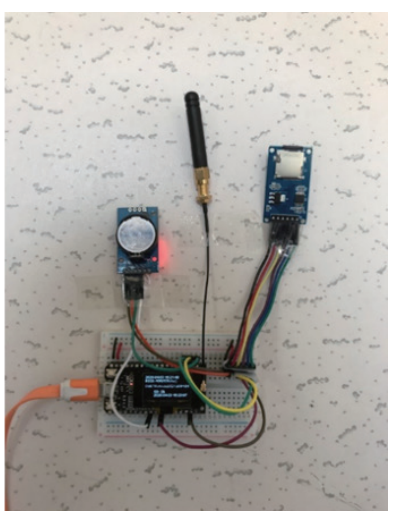

(c)

Fig. 6. (Color online) Photographs of the (a) end node, (b) gateway, and (c) gateway node. 


\section{Experimental Results}

The field test of the proposed sensor node was conducted at the Daejeon weather station in South Korea for 7 days from 3 to 10 April 2020. Figure 7 shows the test setup used to evaluate the observation performance of the road surface temperature on the asphalt. The prototype attached to the side of the sign stand remotely measures the temperature through an IR sensor, and a platinum resistance thermometer validated by the Korea Verification Agency directly measures the temperature of the surface of the asphalt.

\subsection{Results of the field test}

Figure 8 shows time series of the asphalt surface temperature obtained with the MLX90614 and the platinum resistance thermometer (PRT) sensors. First, the mean daily temperature recorded by the MLX90614 sensor (red line) was $1.63{ }^{\circ} \mathrm{C}$ lower than that recorded by the PRT sensor (grey line). The difference was $2.50{ }^{\circ} \mathrm{C}$ during the daytime and $0.64{ }^{\circ} \mathrm{C}$ at night, reflecting the influence of sunlight.

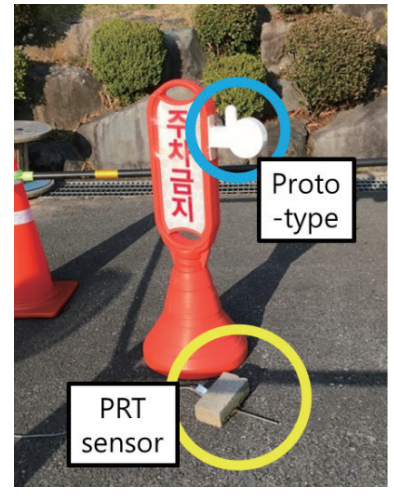

(a)

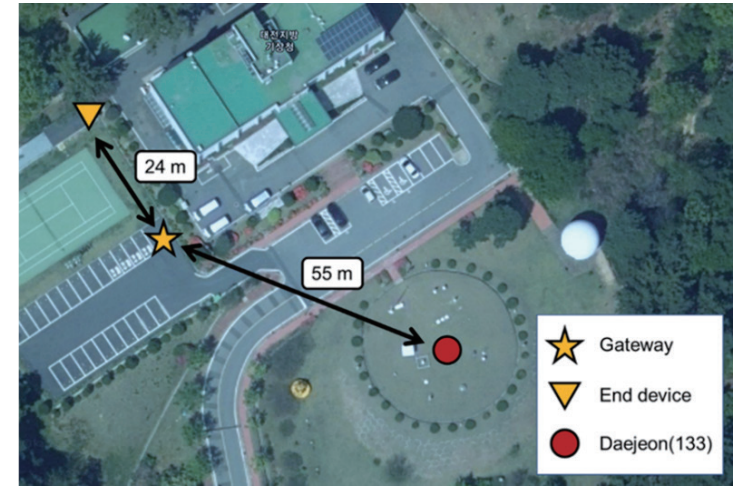

(b)

Fig. 7. (Color online) Field test setup. (a) Applying the prototype with the PRT sensor and (b) positions of devices of the road environment forecast system at the Daejeon weather station.

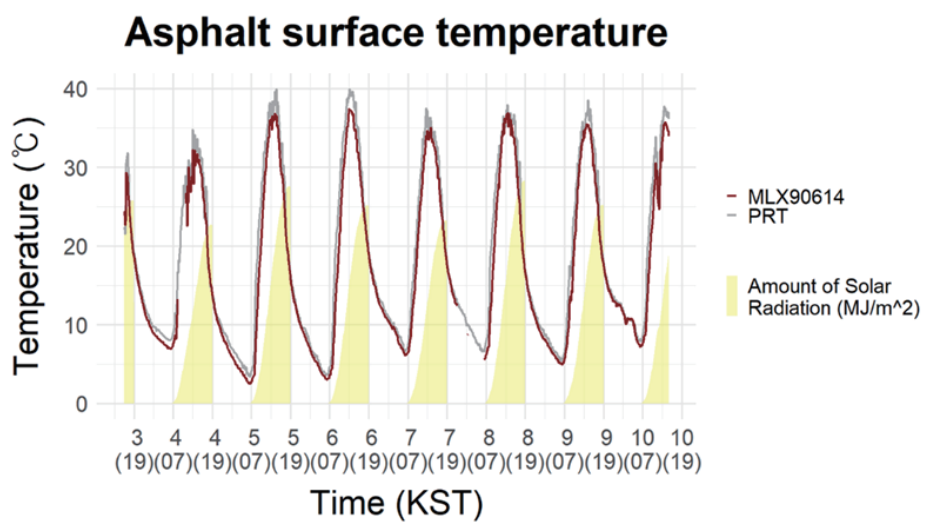

Fig. 8. (Color online) Time series of the asphalt surface temperature obtained with MLX90614 and PRT sensors. 


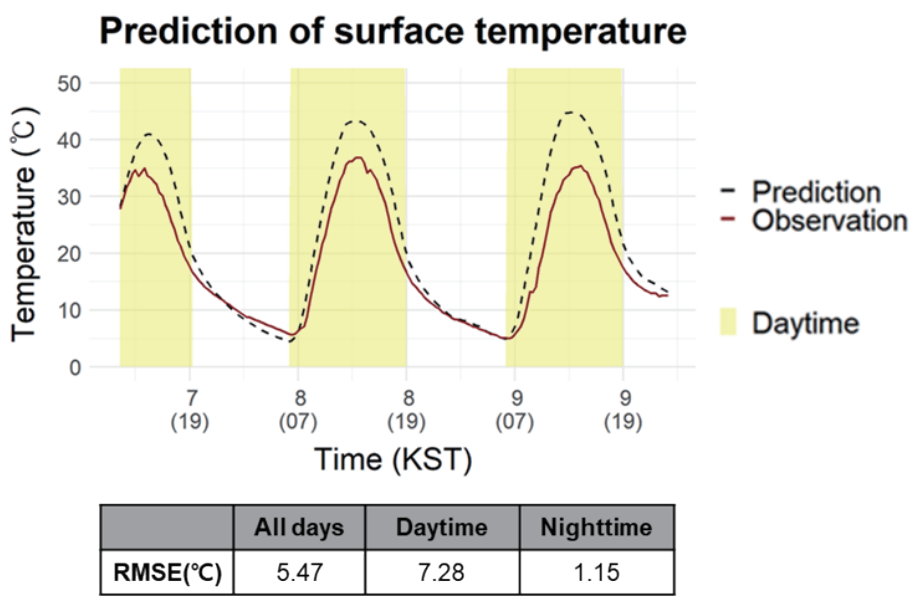

Fig. 9 (Color online) Result of road surface temperature prediction.

\subsection{Result of road surface temperature prediction}

The METRo model is used not only to develop the proposed road weather sensor node, but also to predict the temperature of the asphalt pavement surface in this study. Figure 9 shows the result of the road surface temperature prediction. The root mean square error (RMSE) over $51 \mathrm{~h}$ between the data observed with the prototype and the model is $5.47{ }^{\circ} \mathrm{C}$. There is a large difference between the RMSE for daytime and nighttime: it is $7.28{ }^{\circ} \mathrm{C}$ for daytime and $1.15{ }^{\circ} \mathrm{C}$ for nighttime.

\section{Conclusions}

A compact weather sensor node for predicting the road surface temperature was presented. The proposed node was designed to be compact and use a numerical model for forecasting road conditions. Assuming the air and road surface temperatures to be key parameters for the model, we fabricated the prototype of the sensor node. In field tests, the prototype showed a $1.63{ }^{\circ} \mathrm{C}$ lower temperature than a platinum resistance thermometer during the test period, but the difference was only at $0.64{ }^{\circ} \mathrm{C}$ at night. The result of the prediction showed a large RMSE of $5.47{ }^{\circ} \mathrm{C}$ over $51 \mathrm{~h}$. However, the RMSE was reduced to $1.15^{\circ} \mathrm{C}$ for nighttime measurements. The proposed weather sensor node can be used as part of an economical road infrastructure monitoring system as an alternative to the existing RWIS. It will be beneficial for predicting ice formation on roads because the forecast model shows good performance when there is no impact of sunlight.

\section{Acknowledgments}

This work was supported by the BrainKorea21Plus (BK21Plus) Program. 


\section{References}

1 S. W. Shim and K. C. Choi: KSCE J. Civ. 29 (2009) 685.

2 National Research Council: Where the Weather Meets the Road: A Research Agenda for Improving Road Weather Services (National Academies Press, Washington D.C., 2004) 16.

3 P. Jonsson and M. Riehm: J. Atmos. Oceanic Technol. 29 (2012) 846.

4 L-P. Crevier and Y. Delage: J. Appl. Meteorol. 40 (2001) 1226.

5 T. E. Bell: Science 101: Weather (Harper Collins, New York, 2007) p. 130.

6 M. Kangas, M. Heikinheimo, and M. Hippi: Meteorol. Appl. 22 (2015) 544.

\section{About the Authors}

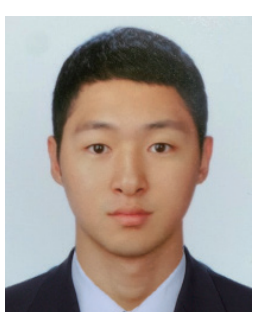

Taeyoon Eom received his B.S. degree in atmospheric science from Kongju National University, Chungcheongnam, Republic of Korea, in 2017 and will obtain his M.S. degree in electronics engineering from Chungnam National University, Korea in 2021. From 2016 to 2019, he worked with the Korea Meteorological Administration (KMA) and is currently working with the Korea Institute of Science and Technology Information (KISTI) as a researcher. His current research interests focus on embedded IoT systems for weather observation.

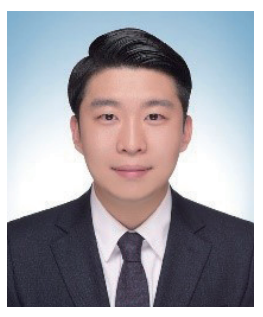

Yongsu Kwon received his B.S. degree in physics from Chungnam National University, Daejeon, Republic of Korea, in 2019. He is currently pursuing his M.S. degree in electronics engineering at the same university. His current research interests are the design of CMOS analog and mixed-mode integrated circuits.

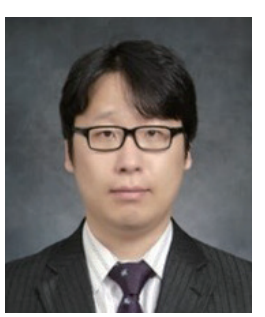

Hyoungho Ko received his B.S. and Ph.D. degrees in electrical engineering from Seoul National University, Republic of Korea, in 2003 and 2008, respectively. From 2008 to 2010, he worked with Samsung Electronics as a senior engineer. In 2010, he joined the Department of Electronics Engineering at Chungnam National University, Republic of Korea, where he is currently an associate professor. His current research interests are the design of CMOS analog and mixed-mode integrated circuits. 